\title{
AOPPs Induce MCP-1 Expression by Increasing ROS-Mediated Activation of the NF-kB Pathway in Rat Mesangial Cells: Inhibition by Sesquiterpene Lactones
}

\author{
Jian-Cheng Wang ${ }^{\mathrm{a}} \quad$ Yan Zhao $^{\mathrm{a}} \quad \mathrm{Si}^{-J i a}$ Chen ${ }^{\mathrm{a}}$ Jing Long ${ }^{\mathrm{b}}$ Qian-Qian Jia \\ Jia-Dai Zhaib Quan Zhang ${ }^{b}$ Yue Chen $^{\mathrm{b}}$ Hai-Bo Long ${ }^{\mathrm{a}}$ \\ aDivision of Nephrology, Zhujiang Hospital, Southern Medical University, Guangzhou, Guangdong, \\ ${ }^{b}$ College of Pharmacy, The State Key Laboratory of Elemento-Organic Chemistry and Tianjin Key \\ Laboratory of Molecular Drug Research, Nankai University, Tianjin, P.R. China
}

\section{Key Words}

MCP-1 - Advanced oxidation protein products - Reactive oxygen species - Nuclear factorkappa B • Sesquiterpene lactones

\begin{abstract}
Background: Monocyte chemoattractant protein-1 (MCP-1) plays an important role in extracellular matrix accumulation through macrophage recruitment and activation in the development and progression of diabetic nephropathy. Therefore, this study examined whether advanced oxidation protein products (AOPPs) are involved in nuclear factor-KB (NF$\mathrm{KB}$ ) activation and MCP-1 mRNA and protein expression in mesangial cells (MCs) and evaluated the effects of derivatives of sesquiterpene lactones (SLs) on AOPP-induced renal damage. Methods: MCP-1 mRNA and protein expression in MCs were determined by quantitative realtime PCR and ELISA, respectively. The level of intracellular reactive oxygen species (ROS) was determined by flow cytometry. The protein expression of tubulin, P47, NF-kB p65, phosphoNF-кB p65, IкB, phospho-IкB, IKK $\beta$ and phospho-IKK $\beta$ was evaluated by Western blot. Results: AOPPs caused oxidative stress in MCs and activated the NF-KB pathway by inducing IKB $\alpha$ phosphorylation and degradation. Inhibition of ROS by SOD (ROS inhibitor) blocked the AOPPmediated NF-KB pathway. Moreover, the inhibition of AOPP-induced overproduction of MCP1 mRNA and protein was associated with inhibition of IKB $\alpha$ degradation by SLs. Conclusion: AOPPs induce MCP-1 expression by activating the ROS/NF-KB pathway and can be inhibited by SLs. These findings may provide a novel approach to treat inflammatory and immune renal diseases, including diabetic nephropathy.
\end{abstract}

Copyright (C) 2013 S. Karger AG, Basel 
Wang et al.: Sesquiterpene Lactones Inhibit AOPP-Induced MCP-1 Expression

\section{Introduction}

Diabetic nephropathy (DN) is one of the most prevalent and serious microvascular complications of diabetes and is a leading cause of end-stage renal disease (ESRD) [1]. The pathologic features of DN include mesangial and matrix glomerular hypertrophy and thickening of the glomerular basement membrane (GBM), which results in progressive renal impairment and glomerulosclerosis [2]. Glomerular mesangial cells are considered to be important players in the pathogenesis of DN [3] because mesangium expansion is consistently observed in DN patients, and the ever-increasing extracellular matrix (ECM) deposition has generally been considered to be critical in the pathogenesis of the disease [2]. Previous studies have indicated that MCs overexpress ECM in the presence of a high concentration of glucose and advanced glycation end products [3, 4]. Monocyte chemoattractant protein-1 (MCP-1), which is a member of the C-C chemokines, is mainly secreted by MCs and upregulated in many renal diseases, including DN $[5,6]$. MCP-1 is involved in the pathogenesis of $\mathrm{DN}$, particularly inflammation, which is regulated by NF- $\mathrm{KB}$ signaling $[7,8]$. The role of MCP-1 in ECM accumulation under diabetic conditions suggests that this protein may be involved in ECM synthesis [5].

Advanced oxidation protein products (AOPPs) are a novel class of renal pathogenic mediators that have been found to be involved in not only obesity and metabolic syndrome but also diabetic patients with or without microvascular complications [9]. AOPPs are uremic toxins that were first identified and reported by Witko-Sarsat in 1996 and contain dityrosine and cross-linking protein products formed during oxidative stress as a result of a reaction between chlorinated oxidants and plasma proteins. They are considered to be the true mediators of the proinflammatory effects of oxidative stress in uremia $[10,11]$. Taken together, these data suggest that oxidized proteins can induce oxidative stress. However, whether AOPP accumulation affects mesangial cell function and its main signaling pathway is not clear. Thus, in the present study, we examined whether AOPP-induced reactive oxygen species (ROS) and the main signaling pathway are involved in NF- $\kappa B$ activation as an approach for understanding the upstream regulation of AOPP-induced NF- $\kappa B$ activation in MCs. We also evaluated the role of NF- $\kappa B$ activation in MCP-1 mRNA and protein expression in MCs cultured in the presence of AOPPs to determine the biologic significance of NF- $\kappa B$ activation.

Parthenolide, which is a natural sesquiterpene lactone (SL) isolated from the medicinal herb feverfew, is used to treat migraines, inflammation and arthritis [12]. Parthenolide and other SLs have been reported to have anti-inflammatory activities by inhibiting NF$\kappa \mathrm{B}$, and parthenolide has been reported to inhibit nuclear factor kappa-B kinase (IKK) and/or directly inactivate NF- $\kappa B[13,14]$. Other studies have indicated that parthenolide blocks MCP-1 mRNA and protein expression, which are associated with inhibition of IKK activity, preservation of I $\kappa \mathrm{B}$ and inhibition of NF- $\kappa \mathrm{B}$ translocation [7]. Recent studies have demonstrated that PTL can inhibit inflammatory factors in human renal mesangial cells under hyperglycemic conditions [15]. Jordan et al. reported that PTL can selectively eradicate acute myeloid leukemia (AML) stem and progenitor cells through NF- $\mathrm{kB}$ inhibition and ROS generation [16], and the water-soluble form of PTL (DMAPT) is currently being tested in a clinical trial. Micheliolide (MCL), which is a naturally occurring guaianolide sesquiterpene lactone, can also selectively inhibit AML stem and progenitor cells. Moreover, its watersoluble form, DMAMCL, has been demonstrated to have superior efficacy compared to DMAPT for treatment in an acute leukemia mice model [17].

In the present study, we investigated the molecular mechanisms underlying AOPPinduced MCP-1 expression in cultured rat MCs. Here, we show that the AOPP-induced expression of MCP-1 in MCs is mediated through activation of the NF- $\mathrm{BB}$ signaling pathway, following ROS generation. Furthermore, some SLs and their derivatives (Fig. 1A) were found to prevent NF- $\kappa B$ activation and subsequent MCP-1 mRNA and protein expression. 
Fig. 1. (A) Structures of the natural SLs and synthetic derivatives. (B) The synthesis of MCL, arglabin, 1 and 2 started with parthenolide. (C) Synthesis of the di-spirocyclopropyl analogue. (D) Synthesis of compounds 4 and 5.

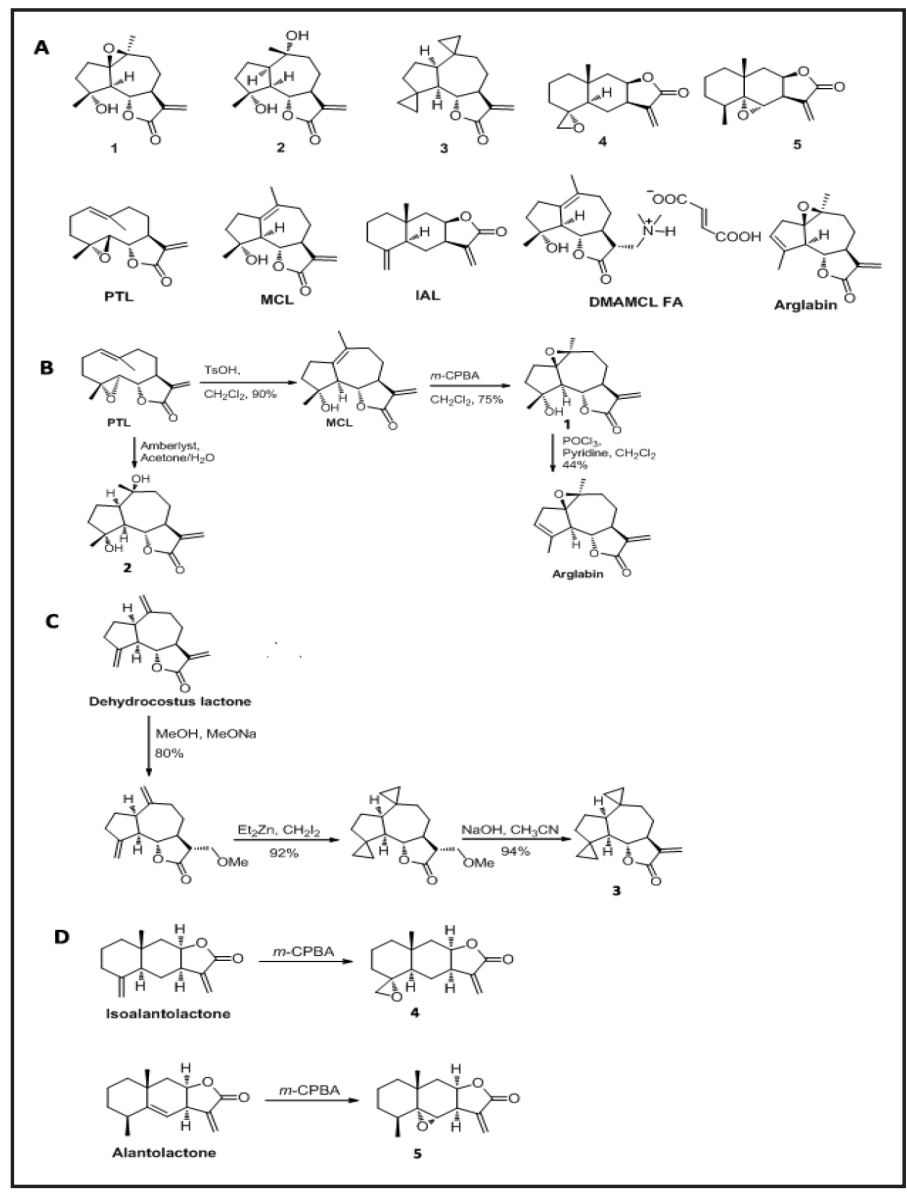

\section{Materials and Methods}

\section{AOPPs-RSA Preparation and Determination}

AOPPs-rat serum albumin (AOPPs-RSA) was prepared according to a previously described method. Briefly, RSA solution $(100 \mathrm{mg} / \mathrm{ml})$ was exposed to $200 \mathrm{mM} \mathrm{HOCl}$ at a molar ratio of $1 / 140$ for $30 \mathrm{~min}$ at $37^{\circ} \mathrm{C}$ and was then dialyzed against phosphate-buffered saline (PBS) to remove free HOCl. The AOPP preparation was passed through a Detoxi-Gel column (Pierce, USA) to remove contaminated endotoxin. The endotoxin levels in the preparation were measured with a Limulus Amoebocyte Lysate kit (Sigma-Aldrich, USA) and were found to be below $0.025 \mathrm{EU} / \mathrm{ml}$. The AOPP content was determined by measuring the absorbance at $340 \mathrm{~nm}$ in an acidic condition and was calibrated with chloramines-T in the presence of potassium iodide. The AOPP content in the AOPPs-RSA and unmodified RSA was $57.88 \pm 4.21$ and $0.2 \pm 0.06 \mathrm{nmol} / \mathrm{g}$ protein, respectively.

\section{Cell Culture}

Rat glomerular MCs (HBZY-1, Life-Science Academy of Wuhan University, Wuhan, China) were cultured and maintained in DMEM, containing $5.6 \mathrm{mmol} / \mathrm{L}$ glucose supplemented with $10 \%$ fetal bovine serum (FBS), $100 \mathrm{U} / \mathrm{ml}$ penicillin and $100 \mu \mathrm{g} / \mathrm{ml}$ streptomycin in a humidified atmosphere with $5 \% \mathrm{CO}_{2}$ at $37^{\circ} \mathrm{C}$. The mesangial cells were serum-deprived for $24 \mathrm{~h}$ prior to the experiment. The cells were cultured in a 100-mm culture dish for western blot analysis on a cover glass coated with polylysine for intracellular ROS measurement and a 6-well culture plate for quantitative real-time PCR and ELISA.

\section{Determination of Intracellular ROS by Flow Cytometry}

The level of intracellular ROS was determined by measuring samples with the oxidation-sensitive fluorescent probe $2^{\prime}, 7^{\prime}$-dichlorofluorescein diacetate (DCFH-DA) (Sigma-Aldrich, USA). This compound readily diffuses into cells and is deacetylated to form nonfluorescent $2^{\prime}, 7^{\prime}$-dichlorofluorescein (DCFH), which 
Wang et al.: Sesquiterpene Lactones Inhibit AOPP-Induced MCP-1 Expression

emits fluorescence when DCFH reacts with ROS to form the highly fluorescent 2',7'-dichlorofluorescein (DCF). The cells were washed with D-Hank's solution and then incubated with $10 \mu \mathrm{M}$ of DCFH-DA for 30 min at $37^{\circ} \mathrm{C}$. The distribution of DCF fluorescence in the cells was detected using a flow cytometer with a wavelength of $488 \mathrm{~nm}$ for excitation and $525 \mathrm{~nm}$ for emission.

Measurements of MCP-1 by ELISA

Culture supernatants were collected from various experimental conditions, centrifuged to remove the cell debris, and stored at $-80^{\circ} \mathrm{C}$ for analysis. The MCP-1 protein concentration was measured using an enzyme-linked immunosorbent assay (ELISA) kit (Ebioscience Inc., USA). According to the manufacturer's instructions, the ELISA kit for MCP-1 is specific for rat MCP-1 and has a sensitivity of $4.7 \mathrm{pg} / \mathrm{ml}$. The standard curve range was 7.8-500 pg/ml, and the results were corrected for the cell count.

Quantitative Real-time PCR ( $q$ PCR) Analysis

To validate MCP-1 gene expression in all of the cell samples, the total RNA was isolated from the cell lines, and cDNA synthesis was performed using TRIzol and Oligo dT (Invitrogen, USA). The qPCR assay was performed using the SYBER Green assay (Applied Biosystems, USA). The amplification conditions were as follows: $95^{\circ} \mathrm{C}$ for $3 \mathrm{~min}$, followed by 40 cycles of $95^{\circ} \mathrm{C}$ for $15 \mathrm{~s}$ and $60^{\circ} \mathrm{C}$ for $30 \mathrm{~s}$. Thermal cycling and fluorescence detection were performed using the StepOnePlus ${ }^{\mathrm{TM}}$ Real-Time PCR System (Applied Biosystems, USA). MCP-1 mRNA expression relative to GAPDH expression was determined using the $\Delta \mathrm{Ct}$ method. All of the primers for qRT-PCR were designed with Primer Express software (ABI). The primer sequences were as follows: MCP-1 ( \pm ) TAGCATCCACGTGCTGTCTC/ CCGACTCATTGGGATCATCT and GAPDH ( \pm ) ATTGTCAGCAATGCATCCTG/ ATGGACTGTGGTCATGAGCC. The expression level was analyzed using the 2-DDCt method.

\section{Western blot analysis}

All of the samples were rinsed three times with ice-cold PBS and dissolved in lysis buffer containing $1 \mathrm{mM}$ phenylmethylsulfonyl fluoride (PMSF) for $25 \mathrm{~min}$ on ice. The lysates were centrifuged $(12,000$ $\times \mathrm{g}$ ) at $4^{\circ} \mathrm{C}$ for $15 \mathrm{~min}$, and then the proteins were boiled in loading buffer for $5 \mathrm{~min}$ and blotted onto a polyvinylidene difluoride (PVDF) membrane after they were separated on a $10 \%$ Tris-glycine gradient gel. The non-specific binding sites were blocked by immersing the membrane in $5 \%$ non-fat milk in Trisbuffered saline (TBS) solution for $1 \mathrm{~h}$ and then incubated with the primary antibody overnight at $4^{\circ} \mathrm{C}$. The membrane was then washed in Tris-buffered saline (TBS) with $0.01 \%$ Tween 20 before being incubated with the respective secondary antibody for $1 \mathrm{~h}$ at room temperature. Electrochemiluminescence (ECL, Amersham Biosciences, USA) detection was performed, and the images were captured and documented using a CCD system (Imagestation 2000MM, Kodak, USA). The quantitative analysis of these images was performed using ImageJ, and the optical density was normalized against tubulin.

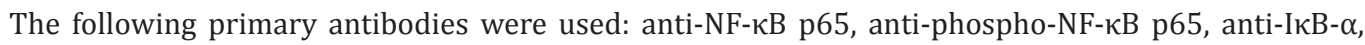
anti-phospho-IкB- $\alpha$, anti-IKK- $\beta$, anti-phospho-IKK- $\beta$ (Cell Signaling Technology, USA), and anti-P47phox (Santa Cruz Biotechnology, USA).

\section{Data analysis}

The results are expressed as the mean \pm standard error of the mean (SEM) from at least three independent experiments. The statistical significance of the differences between the test groups was assessed by oneway analysis of variance (ANOVA) followed by Scheffe's test (post-hoc). Statistical significance was defined as $\mathrm{P}<0.05$.

\section{Results}

AOPPs induce NADPH oxidase-dependent ROS production in MCS

To determine whether AOPPs could induce ROS production in MCs, we used the fluorescent probe DCFH-DA to measure ROS generation in MCs. We found that treatment with AOPPs induced a significant increase in ROS (Fig. 2A). NADPH oxidase is an important source of ROS production. Therefore, to determine whether ROS was generated by NADPH oxidase, 


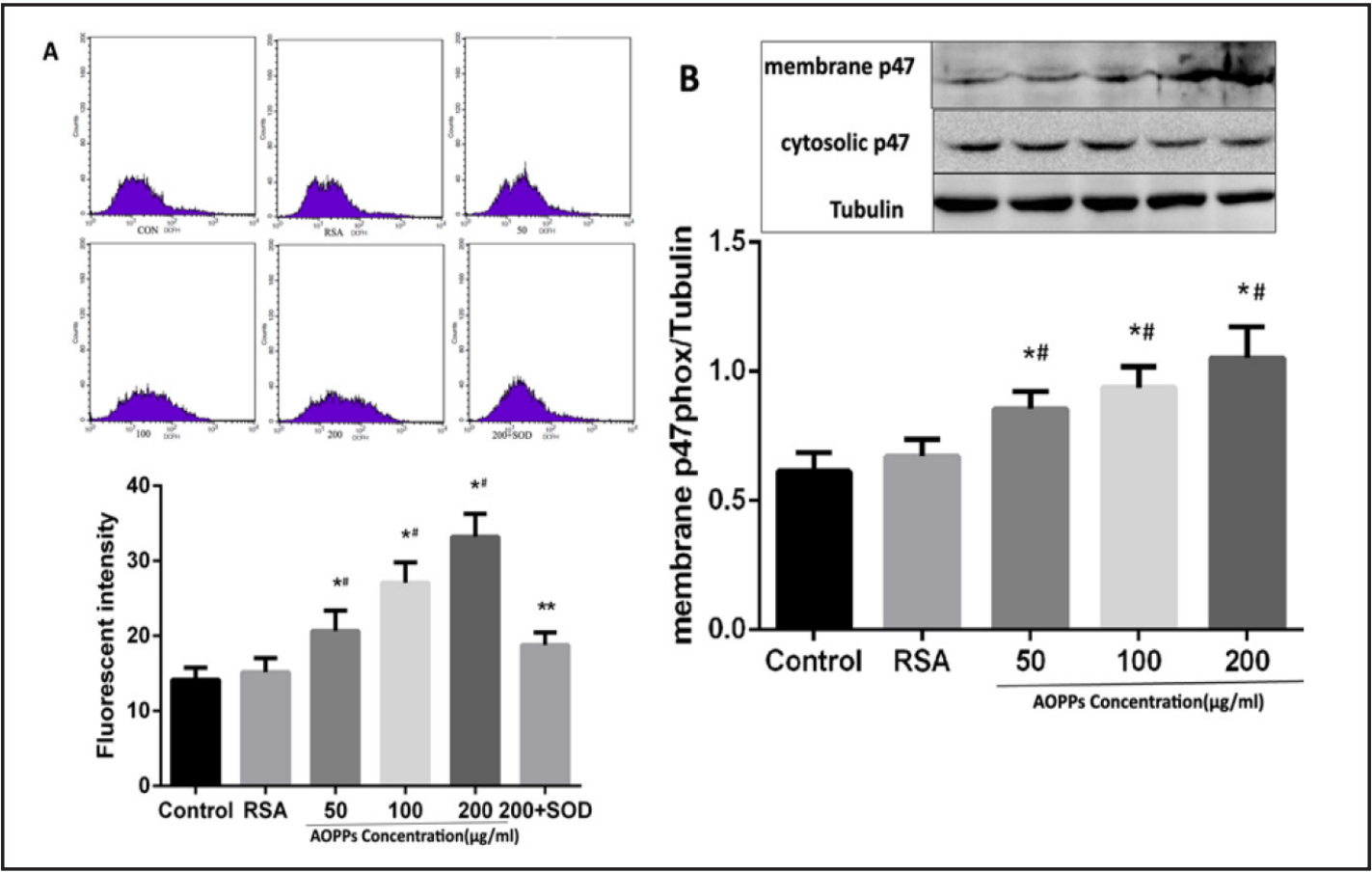

Fig. 2. AOPPs induce NADPH oxidase-dependent ROS production in cultured MCs. (A) MCs were incubated with the different concentrations of AOPPs and $200 \mu \mathrm{g} / \mathrm{ml}$ of RSA for $1 \mathrm{~h}$. The intracellular ROS were measured using the fluorescent probe DCFH-DA. (B) To verify the source of ROS generation, the experiments showed that AOPPs induce p47phox membrane translocation. The data are expressed as the mean \pm SD of three independent experiments. p $<0.05$ for 50,100 , and $200 \mu \mathrm{g} / \mathrm{ml}$ of AOPPs. ${ }^{*} \mathrm{p}<0.05 \mathrm{vs}$. control, ${ }^{* *} \mathrm{p}<0.05$ vs. AOPP-treatment group, $\# \mathrm{p}<0.05$ vs. RSA-treatment group.

the activated form of NADPH oxidase was assessed. The activated form of NADPH oxidase is a multimeric protein complex consisting of at least three cytosolic subunits (p40phox, p47phox and p67phox). Phosphorylation of p47phox leads to a conformational change, which allows for its interaction with p22phox and is indicative of NADPH activation [18]. Therefore, we determined the effect of AOPPs on NADPH oxidase activation by assessing the translocation of p47phox in MCs (Fig. 2B). Our results showed that AOPPs induce a significant p47phox membrane translocation with a maximal response at $200 \mu \mathrm{g} / \mathrm{ml}$. Together, these results indicate that AOPPs induce ROS generation by increasing NADPH oxidase activity.

\section{Activation of IKK $\mathrm{I}$, $\kappa B \alpha$ and $N F-\kappa B$}

The NF- $\kappa B$ pathway is a key component of the cellular response to a variety of extracellular stimuli. Therefore, we assessed whether AOPPs play a role in the regulation of this transcription factor by examining the phosphorylation of IKK $\beta, I \kappa B \alpha$ and NF- $\kappa B$ and the degradation of IкB $\alpha$ in MCs. The results showed a significant dose-dependent

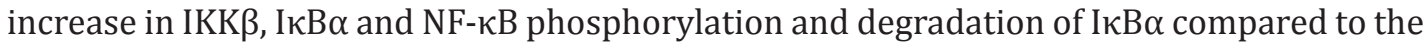
respective control group, without any change in the total protein content of IKK $\beta$ and NF- $\kappa B$. Pretreatment of MCs with SOD (ROS inhibitor) almost completely inhibited NF- $\kappa B$ activation, so AOPP-induced ROS production and the main signaling pathway are involved in NF- $\kappa B$ activation (Fig. 3A, B and C).

\section{AOPPs induce MCP-1 $\mathrm{mRNA}$ and protein expression}

To determine the effect of AOPPs on MCP-1 expression, MCs were treated with AOPPs for up to $24 \mathrm{~h}$, and then the MCP-1 activity and protein expression in the cell medium were determined by ELISA. Exposure to AOPPs induced MCP-1 protein expression in a dose- 


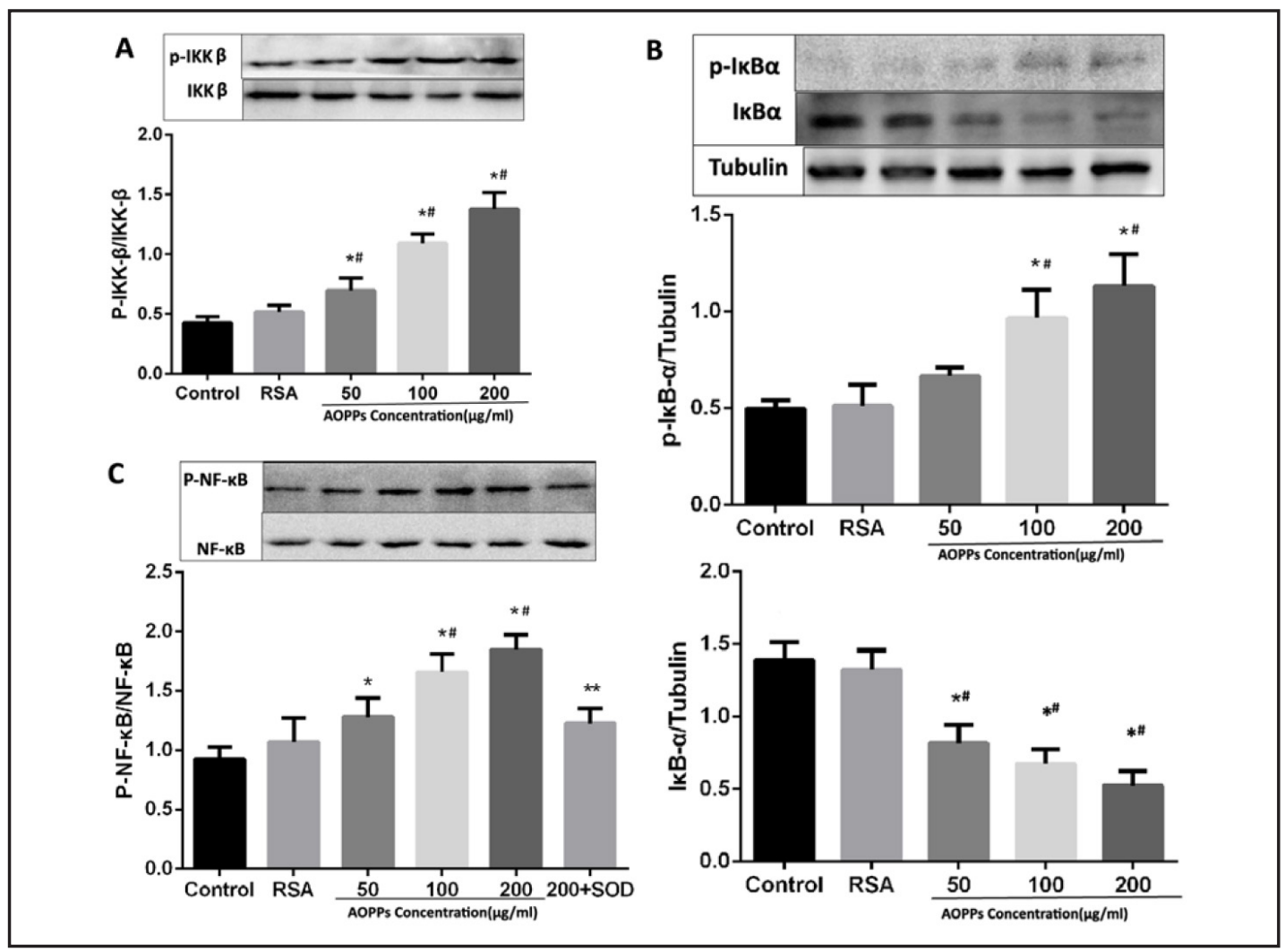

Fig. 3. AOPP-induced phosphorylation of IKK $\beta$, I $\kappa \mathrm{B} \alpha$ and NF- $\kappa \mathrm{B}$ and degradation of $\mathrm{I} \kappa \mathrm{B} \alpha$ in cultured MCs. (C, $D$ and E) Representative western blot for NF- $\kappa B$ expression in MCs treated with the different concentrations of AOPPs and $200 \mu \mathrm{g} / \mathrm{ml}$ of RSA for $1 \mathrm{~h}$. Incubation with AOPPs induced phosphorylation of IKK $\beta$, IкB $\alpha$ and NF- $\kappa B$ and degradation of $\mathrm{I} \kappa \mathrm{B} \alpha$. Pretreatment of MCs with SOD almost completely inhibited NF- $\kappa \mathrm{B}$ activation. The data are expressed as the mean \pm SD of three independent experiments. $p<0.05$ for 50,100 , and 200 $\mu \mathrm{g} / \mathrm{ml}$ of AOPPs. ${ }^{*} \mathrm{p}<0.05$ vs. control, ${ }^{* *} \mathrm{p}<0.05$ vs. AOPP-treatment group, $\# \mathrm{p}<0.05$ vs. RSA-treatment group.

dependent manner (Fig. 4A), and a significant increase in MCP-1 protein expression was observed after $24 \mathrm{~h}$ of incubation. This result suggests that AOPP-mediated induction of MCP-1 expression occurs at the transcriptional and translational levels. To further examine whether the increase in MCP-1 activity by AOPPs was a result of increased MCP-1 mRNA expression, MCP-1 mRNA expression in the MCs was determined by q-PCR. AOPPs induced MCP-1 mRNA accumulation in a dose-dependent manner in the MCs (Fig. 4B). These results further suggest that AOPPs induce MCP-1 expression at the transcriptional and translational levels.

Treatment with SLs Prevents AOPP-induced MCP-1 mRNA and protein expression

MCP-1 protein expression in the MCs was significantly up-regulated by AOPPs (200 $\mu \mathrm{g} / \mathrm{ml}$ ) compared to the control group. In addition, treatment with the NF- $\mathrm{BB}$ inhibitor SLs ( 5 and $10 \mu \mathrm{mol} / \mathrm{L}$ ) reduced the AOPP-mediated increase in MCP-1 protein expression in a dose-dependent manner in the MCs (Fig. 4C), suggesting that NF- $\kappa B$ signaling participates in this regulation. Thus, SLs have clear effects on MCP-1 production in MCs, indicating that SLs are involved in reducing inflammation. To further examine whether the decrease in MCP-1 caused by SLs resulted from decreased mRNA expression, the MCP-1 mRNA expression in MCs was determined by qPCR. MCP-1 mRNA expression was significantly up-regulated after incubation with AOPPs $(200 \mu \mathrm{g} / \mathrm{ml})$ compared to the control group. However, treatment with the NF- $\kappa B$ inhibitor SL (5 and $10 \mu \mathrm{mol} / \mathrm{L}$ ) blocked the AOPP-mediated increased in 


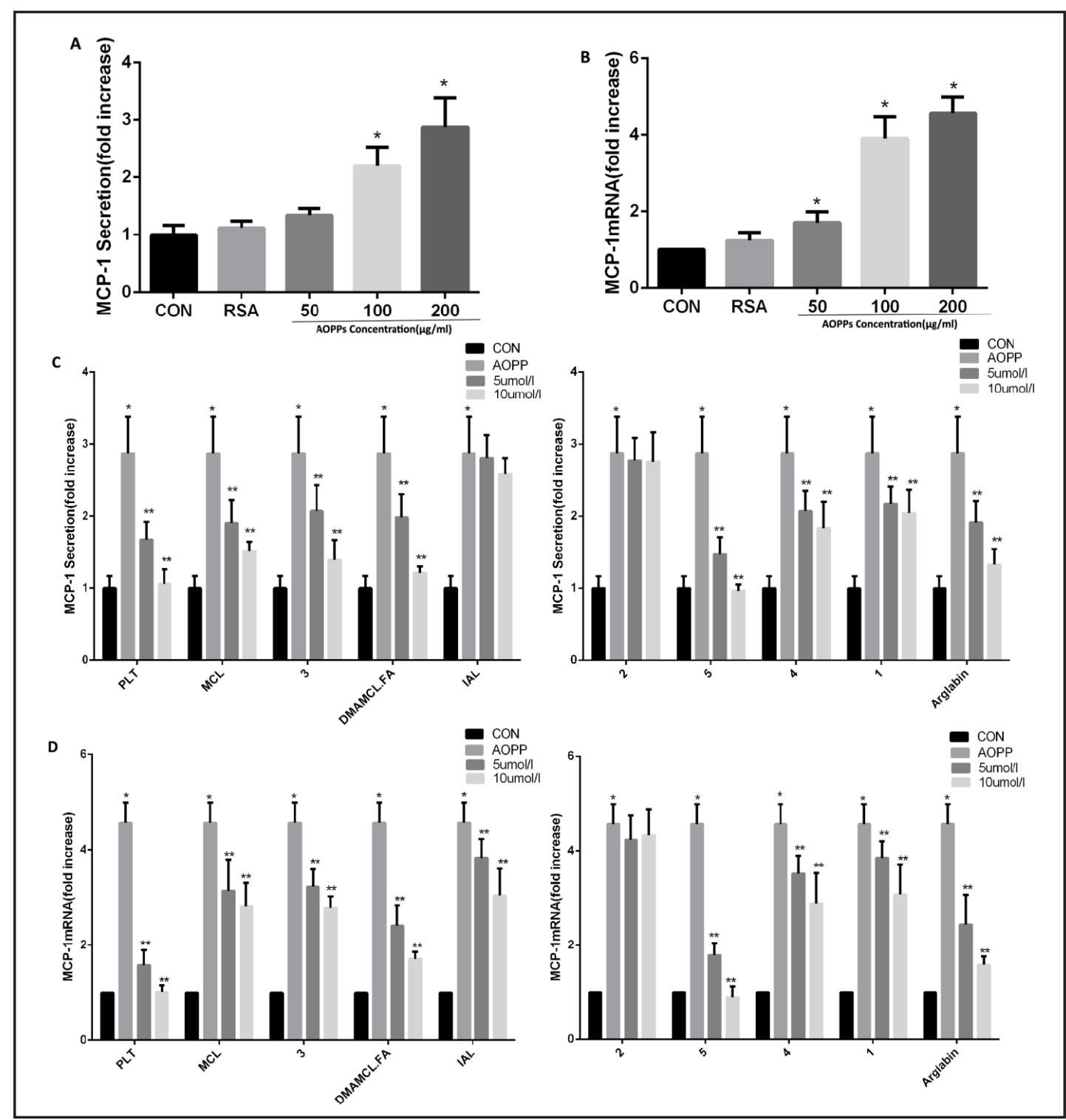

Fig. 4. AOPPs induce MCP-1 mRNA and protein expression in cultured MCs. (A and B) MCs were incubated with the different concentrations of AOPPs and $200 \mu \mathrm{g} / \mathrm{ml}$ of RSA for $24 \mathrm{~h}$. AOPP treatment increased MCP-1 mRNA and protein expression in a dose-dependent manner. SLs prevented AOPP-induced MCP-1 mRNA and protein expression. (C and D) MCs were preincubated for $1 \mathrm{~h}$ with 5 and $10 \mu \mathrm{mol} / \mathrm{L}$ of SLs. Subsequently, the MCs were incubated with AOPPs $(200 \mu \mathrm{g} / \mathrm{ml})$ for $24 \mathrm{~h}$. AOPP treatment increased MCP-1 mRNA and protein expression. SLs prevented AOPP-induced MCP-1 mRNA and protein expression. The data are expressed as the mean \pm SD of three independent experiments. ${ }^{*} \mathrm{p}<0.05$ vs. control, ${ }^{* *} \mathrm{p}<0.05$ vs. AOPP-treatment group.

MCP-1 mRNA expression. These results suggest that SLs reduce MCP-1 expression at the transcriptional and translational levels (Fig. 4D).

\section{Treatment with SLs prevents AOPP-induced IKBa degradation}

We further analyzed whether factors in the NF- $\mathrm{KB}$ activation cascade are influenced by SLs by assessing their effect on IкB proteins using Western blot analysis. MCs were preincubated for $1 \mathrm{~h}$ with 5 or $10 \mu \mathrm{mol} / \mathrm{L}$ of SLs and then subsequently incubated with $200 \mu \mathrm{g} / \mathrm{ml}$ AOPPs for $1 \mathrm{~h}$. The results showed that preincubating the cells with 5 (Fig. 5A) 
Fig. 5. SLs prevented AOPP-induced IкB $\alpha$ degradation. MCs were preincubated for $1 \mathrm{~h}$ with 5 or $10 \mu \mathrm{mol} / \mathrm{L}$ of SLs. Subsequently, the MCs were incubated with AOPPs $(200 \mu \mathrm{g} / \mathrm{ml})$ for $1 \mathrm{~h}$. The AOPPs induced $\mathrm{I} \kappa \mathrm{B} \alpha$ degradation in cultured MCs. The SLs prevented AOPP-induced I $\mathrm{I} B \alpha$ degradation. The effect $10 \mu \mathrm{mol} / \mathrm{L}$ of SLs (B) was better than $5 \mu \mathrm{mol} / \mathrm{L}$ (A) for preventing AOPP-induced I $\kappa \mathrm{B} \alpha$ degradation. The data are expressed as the mean \pm SD of three independent experiments. ${ }^{*} \mathrm{p}<0.05$ vs. control, ${ }^{* *} \mathrm{p}<0.05$ vs. AOPP-treatment group.

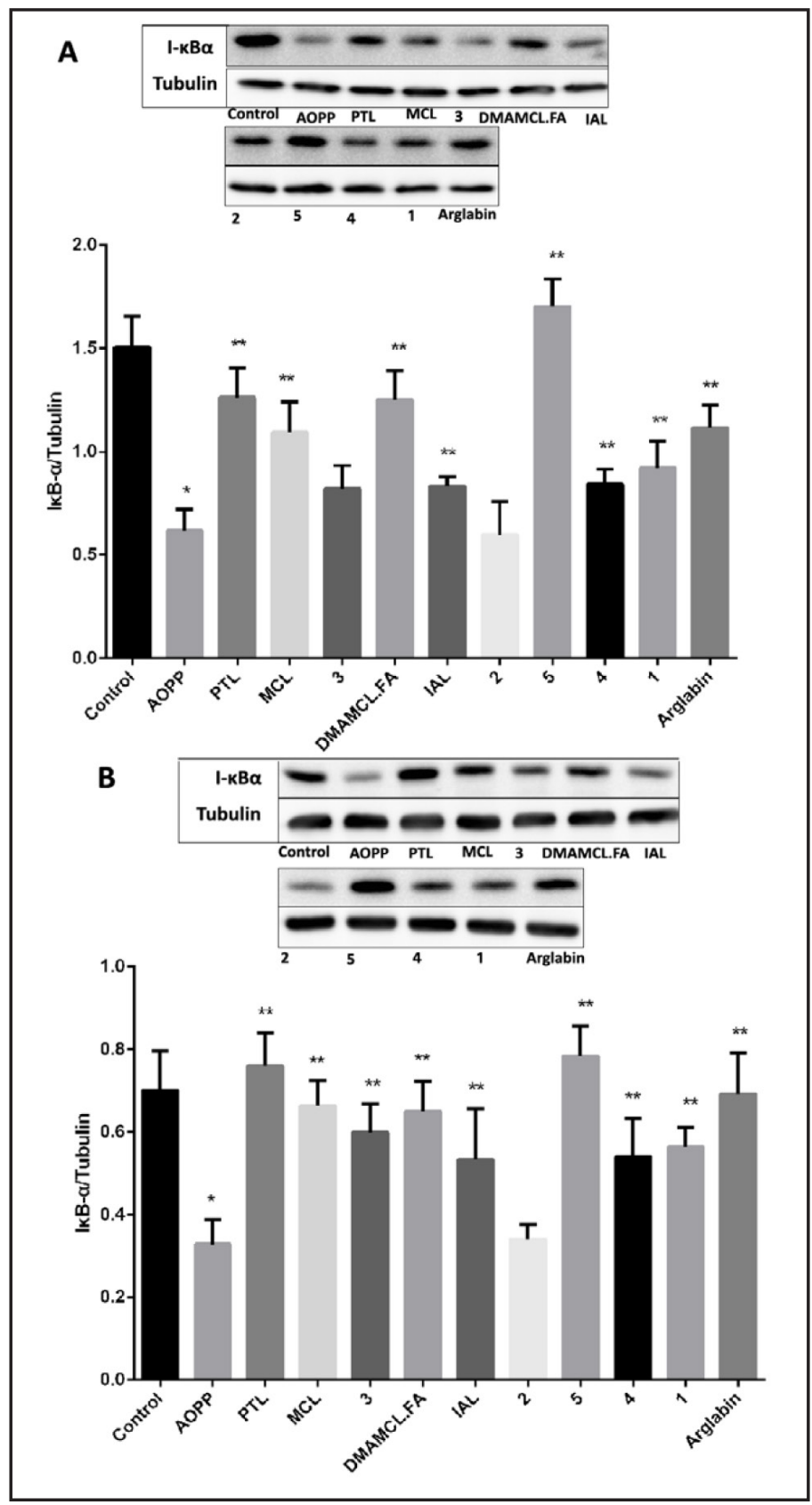

or $10 \mu \mathrm{mol} / \mathrm{L}$ (Fig. 5B) of SLs prevented AOPP-mediated IкB $\alpha$ degradation. These results suggest that SLs can protect IкB $\alpha$ from proteolysis by the $26 \mathrm{~S}$ proteasome and therefore may interfere with a common step in the signaling cascade leading to NF- $\kappa \mathrm{B}$ activation.

\section{Discussion}

This study is the first to demonstrate that AOPPs induce NF- $\kappa B$ activation and MCP-1 expression at the gene and protein levels in MCs, thus confirming the participation of this transcription factor in the pathogenesis of $\mathrm{DN}$. In agreement with previous reports indicating that NF- $\mathrm{KB}$ is required for the full induction of MCP-1 mRNA and protein expression [19], we showed that $200 \mu \mathrm{g} / \mathrm{ml}$ of AOPPs can stimulate a significant increase in MCP-1 mRNA and protein expression through the NF- $\kappa$ B pathway in MCs. 
Wang et al.: Sesquiterpene Lactones Inhibit AOPP-Induced MCP-1 Expression

Fig. 6. AOPP-mediated signaling linked to MCP-1 expression in MCs. AOPP-induced MCP-1 expression is mediated through ROS leading to NF- $\kappa \mathrm{B}$ activation. This signaling pathway might contribute to sustained MCP-1 expression, which has been implicated in DN inflammation. Moreover, SLs can reduce $\mathrm{I} \kappa \mathrm{B}$ degradation, preventing NF- $\kappa \mathrm{B}$ activation and subsequent MCP-1 mRNA and protein expression.

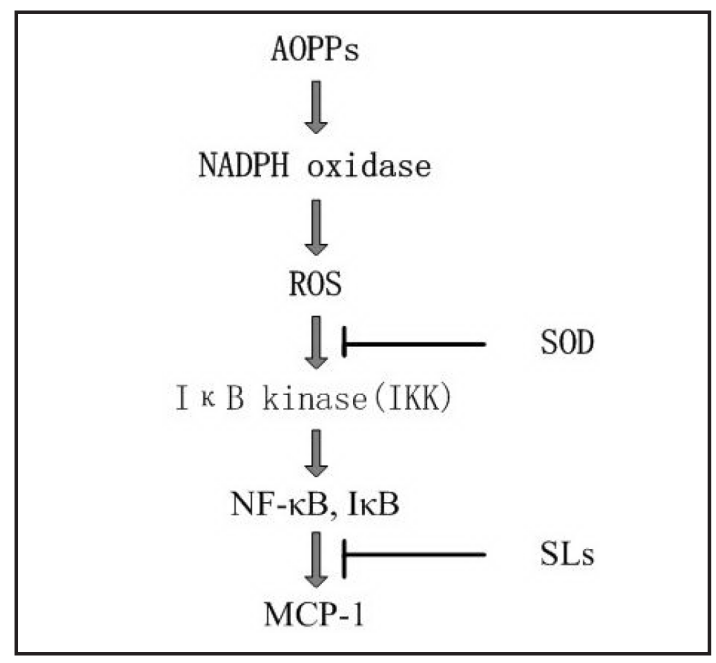

Our results revealed that AOPP treatment of MCs stimulated cellular ROS production by activating NADPH oxidase. NADPH oxidase consists of four cytosolic regulatory subunits (p40phox, p47phox, p67phox, and the small GTPase Rac) and two membrane subunits (p22phox and gp91phox) [18]. Moreover, the specific up-regulation of p47phox, p22phox, and Nox4 has been demonstrated in the kidneys of diabetic patients [20]. This study found that NADPH oxidase activation was due to the translocation of p47phox from the cytosol to the cell membrane. In addition, AOPP treatment induced a significant increase in the ROS level. Previous studies have reported that ROS regulate NF- $\kappa B$ activation [21]. Therefore, we hypothesize that the AOPP-associated activation of the NF- $\kappa B$ signaling pathway occurs through the IKK pathway in MCs. In our study, AOPP-induced MCP-1 mRNA and protein expression and promoter activity were attenuated by SL pretreatment.

The NF- $\kappa$ B family comprises five members, including relA (p65), relB, c-Rel, p105/50, and p100/52, which associate as homo- or heterodimers and are regulated by diverse transduction cascades [22]. The subcellular location of NF- $\kappa \mathrm{B}$ is controlled by a family of

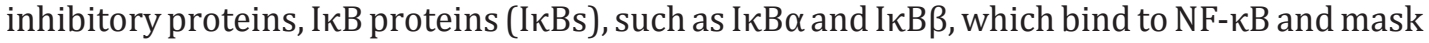
its nuclear localization signal, thereby preventing nuclear uptake. IкBs are phosphorylated by the IKK complex, which leads to ubiquitination and subsequent degradation by the $26 \mathrm{~S}$ proteasome. Generally, proteins in the cytosol and nucleus are degraded via the ubiquitinproteasome pathway, and the $26 \mathrm{~S}$ proteasome is the central protease of the ubiquitindependent pathway of protein degradation and is formed by a barrel-shaped $20 \mathrm{~S}$ core complex and two polar $19 \mathrm{~S}$ complexes to catalyze protein degradation [23, 24]. Finally, the free NF- $\mathrm{KB}$ complexes translocate into the nucleus for target gene transcription activation, and the IкBs are degraded [25]. We demonstrated that AOPPs induce the phosphorylation of IKK $\beta$ and I $\kappa \mathrm{B} \alpha$, resulting in I $\kappa \mathrm{B} \alpha$ degradation and sequela of NF- $\kappa \mathrm{B}$ activation in MCs.

Inflammatory gene expression is regulated by several transcription factors, including $\mathrm{NF}-\kappa \mathrm{B}$. Activation of this transcription factor is a very important step in the development of DN [26]; therefore, the pharmacological modulation of this process is the main objective in the design of new therapies for DN. In this work, we analyzed the effects of the natural compound parthenolide, which is an NF- $\kappa B$ inhibitor, and found that it reduces I $\kappa B$ degradation, preventing NF- $\kappa \mathrm{B}$ activation and subsequent MCP-1 mRNA and protein expression. The inhibition of DNA binding occurs concomitantly with the inhibition of IKB degradation. This finding is in agreement with previous studies on the regulation of interleukin (IL)-8, ICAM-1 and VCAM-1 by parthenolide in several different cell types [27]. To the best of our knowledge, this study is the first to show that SLs protect against DN mainly through NF- $\kappa B$ inhibition (Fig. 6).

The synthesis of SLs was initiated with the easily available PTL (Fig. 1B). PTL was treated with p-toluenesulfonic acid ( $\mathrm{Ts} \mathrm{OH}$ ) to obtain MCL and was then subjected to epoxidation with $\mathrm{m}$-CPBA to yield compound 1 . This compound was then subjected to elimination with POCl3/ 
Wang et al.: Sesquiterpene Lactones Inhibit AOPP-Induced MCP-1 Expression

pyridine to form arglabin (Fig. 1C). PTL was treated under aqueous conditions to generate compound 2. Dehydrocostus lactone was treated with a standard Simmon-Smith reaction. The 11,13-conjugated double bond of the dehydrocostus lactone compound was protected as a Michael adduct [28], and the compound was then converted to a new compound using a Simmon-Smith reaction. Finally, the conjugated double bond was recovered by elimination to create the target compound (compound 3). Compounds 4 and 5 were obtained by the epoxidation of IAL and alantolactone, respectively, with m-CPBA (Fig. 1D) following the previously reported method [29].

Compared to PTL, the other natural and synthetic compounds were substantially more stable and had fewer side effects, although PTL and the other natural and synthetic compounds had similar bioactivities. Thus, the other natural and synthetic compounds may have a broad use in future clinical applications.

In summary, our results suggest that AOPPs induce MCP-1 mRNA and protein expression through a ROS/NF- $\kappa B$-dependent pathway in MCs. Importantly, we found that SLs can exert a beneficial effect in AOPP-induced inflammation and ECM deposition by preventing NF- $\mathrm{B}$ activation in MCs. The natural and synthetic compounds could provide a novel therapeutic approach for treating inflammation during DN.

\section{Conflict of Interest}

The authors declare no competing financial interests.

\section{Acknowledgments}

The present study was supported by the National Natural Science Foundation of China (NSFC) (NO. 81072848 to H.-B. L., NO. 21072106 to Y.C. and 81001377 to Q.Z.) and the Fok Ying Tong Education Foundation (No. 122037).

\section{References}

1 Ritz E, Rychlik I, Locatelli F, Halimi S: End-stage renal failure in type 2 diabetes: a medical catastrophe of worldwide dimensions. Am J Kidney Dis 1999;34:795-808

- Ha H, Lee HB: Reactive oxygen species and matrix remodeling in diabetic kidney: J Am Soc Nephrol 2003;14:S246-S249.

-3 Cohen MP, Hud E, Wu VY, Ziyadeh FN: Albumin modified by Amadori glucose adducts activates mesangial cell type IV collagen gene transcription. Mol Cell Biochem 1995;151:61-67.

4 Ziyadeh FN, Han DC, Cohen JA, Guo J, Cohen MP: Glycated albumin stimulates fibronectin gene expression in glomerular mesangial cells: involvement of the transforming growth factor-beta system. Kidney Int 1998;53:631-638.

-5 Park J, Ryu DR, Li JJ, Jung DS, Kwak SJ, Lee SH, Kim DK, Moon SJ, Kim K, Han DS, Kang SW: MCP-1/CCR2 system is involved in high glucose-induced fibronectin and type IV collagen expression in cultured mesangial cells. Am J Physiol Renal Physiol 2008;295:F749-F757.

6 Lee YS, Cha BY, Saito K, Yamakawa H, Choi SS, Yamaguchi K: Nobiletin improves hyperglycemia and insulin resistance in obese diabetic ob/ob mice. Biochem Pharmacol 2010;79:1674-1683.

7 López-Franco 0, Suzuki Y, Sanjuán G, Blanco J, Hernández-Vargas P, Yo Y, Kopp J, Egido J, Gómez-Guerrero $\mathrm{C}$ : Nuclear Factor- $\mathrm{\kappa B}$ Inhibitors as Potential Novel Anti-Inflammatory Agents for the Treatment of Immune Glomerulonephritis. Am J Pathol 2002;161:1497-1505.

-8 Crunkhorn S: Metabolic disorders: Breaking the links between inflammation and diabetes. Nat Rev Drug Discov 2013;12:261. 
Wang et al.: Sesquiterpene Lactones Inhibit AOPP-Induced MCP-1 Expression

- Kalousova M, Skrha J, Zima T: Advanced glycation end-products and advanced oxidation protein products in patients with diabetes mellitus. Physiol Res 2002;51:597-604.

10 Witko-Sarsat V Friedlander M, Nguyen Khoa T: Advanced oxidation protein products as novel mediators of inflammation and monocyte activation in chronic renal failure. J Imunol 1998;161:2524-2532.

11 Witko-Sarsat V, Friedlander M, Nguyen Khoa T, Capeillère-Blandin C, Nguyen AT, Canteloup S, Dayer JM, Jungers P, Drüeke T, Descamps-Latscha B: AOPP-induced activation of human neutrophll and monocyte oxidative metabolism: a potential target for $\mathrm{N}$-acetylcysteine treatment in dialysis patients. Kidney Int 2003;64:82-91.

12 Pareek A, Suthar M, Rathore GS, Bansal V: Feverfew (Tanacetum parthenium L.):A systematic review. Pharmacogn Rev 2011;5:103-110.

13 Kwok BH, Koh B, Ndubuisi MI, Elofsson M, Crews CM: The anti-inflammatory natural product parthenolide from the medicinal herb Feverfew directly binds to and inhibits IKB kinase. Chem Biol 2001;8:759-766.

14 Mathema VB, Koh YS, Thakuri BC, Sillanpää M: Parthenolide, a Sesquiterpene Lactone, Expresses Multiple Anti-cancer and Anti-inflammatory Activities. Inflammation 2012;35:560-565.

15 Wang W, Wu F, Qian Y, Cheng L, Shao X, Tong X, Li H: Inhibition of inflammatory factors by parthenolide in human renal mesangial cells under hyperglycemic condition. Afr J Biotechnol 2010;9:3458-3463.

16 Guzman ML, Rossi RM, Karnischky L, Li X, Peterson DR, Howard DS, Jordan CT: The sesquiterpene lactone parthenolide induces apoptosis of human acute myelogenous leukemia stem and progenitor cells. Blood 2005;105:4163-4169.

-17 Zhang Q, Lu Y, Ding Y, Zhai J, Ji Q Ma W, Yang M, Fan H, Long J, Tong Z, Shi Y, Jia Y, Han B, Zhang W, Qiu C, Ma X, Li Q, Shi Q Zhang H, Li D, Zhang J, Lin J, Li LY, Gao Y, Chen Y: Guaianolide sesquiterpene lactones, a source to discover agents that selectively inhibit acute myelogenous leukemia stem and progenitor cells. J Med Chem 2012;55:8757-8769.

18 Kleniewska P, Piechota A, Skibska B, Gorąca A: The NADPH Oxidase Family and its Inhibitors. Arch Immunol Ther Exp 2012;60:277-294.

19 Ide Y, Matsui T, Ishibashi Y, Takeuchi M, Yamagishi S: Pigment epithelium-derived factor inhibits advanced glycation end product-elicited mesangial cell damage by blocking NF- $\mathrm{KB}$ activation. Afr J Biotechnol 2010;80:227-232.

20 Li JM, Shah AM: ROS generation by nonphagocytic NADPH oxidase: potential relevance in diabetic nephropathy. J Am Soc Nephrol 2003;14:S221-S226.

21 Morgan MJ, Liu ZG: Crosstalk of reactive oxygen species and NF-кB signaling. Cell Res 2011;21:103-115.

22 Siomek A: NF-кB signaling pathway and free radical impact. Acta Biochim Pol 2012;59:323-331.

23 Takeuchi O, Akira S: Pattern recognition receptors and inflammation. Cell 2010;140:805-820.

24 Voges D, Zwickl P, Baumeister W: THE 26S PROTEASOME: A Molecular Machine Designed for Controlled Proteolysis. Annu Rev Biochem 1999;68:1015-1068.

25 Kiechl S, Wittmann J, Giaccari A, Knoflach M, Willeit P, Bozec A, Moschen AR, Muscogiuri G, Sorice GP, Kireva T, Summerer M, Wirtz S, Luther J, Mielenz D, Billmeier U, Egger G, Mayr A, Oberhollenzer F, Kronenberg F, Orthofer M, Penninger JM, Meigs JB, Bonora E, Tilg H, Willeit J, Schett G: Blockade of receptor activator of nuclear factor- $\mathrm{KB}$ (RANKL) signaling improves hepatic insulin resistance and prevents development of diabetes mellitus. Nat Med 2013;19:358-363.

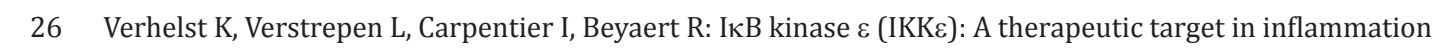
and cancer. Biochem Pharmacol 2013;85:873-880.

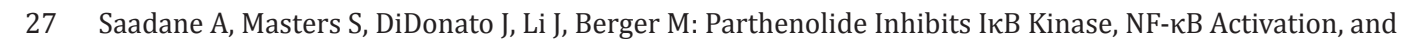
Inflammatory Response in Cystic Fibrosis Cells and Mice. Am J Respir Cell Mol Biol 2007;36:728-736.

28 Matsuda H, Kageura T, Inoue Y, Morikawa T, Yoshikawa M: Absolute stereostructures and syntheses of saussureamines A, B, C, D and E, amino acid-sesquiterpene conjugates with gastroprotective effect, from the roots of Saussurea lappa. Tetrahedron 2000;56:7763-7777.

29 Cantrell CL, Pridgeon JW, Fronczek FR, Becnelb JJ: Structure-activity relationship studies on derivatives of eudesmanolides from Inula helenium as toxicants against Aedes aegypti Larvae and adults. Chem Biodiv 2010;7:1681-1697. 